\title{
THERAPEUTIC PARADOX FROM PENICILLIN THERAPY IN LARYNGEAL SYPHILIS REPORT OF A CASE \\ BY
}

\author{
A. I. SUCHETT-KAYE \\ Senior Medical Registrar, St. Charles' Hospital; London
}

No references could be found in the medical literature to the effect of penicillin in laryngeal syphilis. Larmore (1947), reviewing the treatment of syphilis of the larynx, did not mention the use of penicillin. The following report demonstrates the effects of this antibiotic on one case of syphilitic laryngitis.

\section{Case Report}

A labourer, aged 34, was admitted to St. Charles' Hospital on November 7, 1949, under the care of Dr. A. H. Harkness. The patient complained of general malaise, sore mouth and throat, dysphagia, and rectal discharge of 3 weeks' duration.

There was no definite history of past venereal infection, but in May, 1949, the patient had had a sore on the prepuce, apparently of syphilitic nature, which had healed without treatment. Five months later, he reported to a London V.D. clinic because of a sore throat, painful swelling of the right leg, and ano-rectal discharge. He was diagnosed as a case of acute syphilis and admission to hospital was advised.

On examination at St. Charles' Hospital, he was found to be very ill and toxic. His temperature was $98.8^{\circ} \mathrm{F}$. and the tongue heavily furred. The fauces and palate were covered with large confluent greyish "mucous patches "; these had the appearance of "diphtheritic" pseudo-membrane but could not be removed with a throat-swab. There was also marked bilateral cervical adenitis, rather more pronounced on the right. The voice was slightly husky, but this was not a conspicuous feature and its significance was not realized at the time. The penis showed a recently healed preputial chancre and the glands in the right groin were enlarged, nontender, and of rubbery consistency. Around the anus, confluent areas of condylomatous lesions were present. The patient's skin, however, was clear except for hyperkeratosis and desquamation on the legs and on the plantar aspects of both feet. It was also noticed that the right leg was oedematous from saphenous vein thrombosis.

Investigations.-Dark-ground microscopy of scrapings from the anal condylomata (November 8 ) showed many
Treponemata pallida; no pathogenic organisms were demonstrated from the material collected from the oral and faucial lesions. The Wassermann reaction and the Kahn test were both positive.

Treatment.-Penicillin therapy was commenced on November 8 in three-hourly doses of 100,000 units given intramuscularly. This was discontinued on November 18 , when a total of 8 mega units had been given. On November 14, the patient received the first injection of bismostab $(1.5 \mathrm{ml}$.) and this was continued at weekly intervals up to a total of ten.

Progress.-A typical Herxheimer reaction, with a rise in temperature to $102.4^{\circ} \mathrm{F}$. and rigor, occurred 8 hours after the first dose of penicillin. On the fourth day of treatment the "mucous patches" could not be seen except for a single small area on the palate, to the left of the uvula. The cervical glands had disappeared, leaving only a solitary enlarged gland in the right submaxillary region. The anal condylomata, however, did not heal till the eighth day of penicillin treatment. The rapid healing of all syphilitic lesions was accompanied by a noticeable improvement in the patient's general health. On November 21, circumcision for phimosis, and excision of a small sebaceous scrotal cyst, were performed under general anaesthesia. Whilst the patient was recovering from these minor operations, a gradual but quite definite alteration took place in his voice, leading to a very marked degree of hoarseness but not to complete aphonia. On November 29, the hoarseness became so alarming that a laryngologist was consulted. There was, however, none of the wheezing usually associated with severe laryngeal obstruction. Examination of the larynx with a mirror showed a picture consistent with a syphilitic laryngitis in the course of rapid healing under intensive therapy. The epiglottis and vocal cords showed infiltration, fibrosis, and slight deformity: the arytenoid cartilages looked normal ; the airway was not obstructed.

In December the patient was given a course of $30 \mathrm{gr}$. potassium iodide daily, which was continued until his discharge from hospital on January 9, 1950. No untoward effects resulted from this treatment and no signs of laryngeal stridor developed. Laryngoscopy repeated 
on December 14 showed well-advanced epiglottic scarring, but the airway still remained free. The hoarseness was much less marked. Early in January, 1950, serological tests were still positive, but on January 17 the Wassermann reaction was reported \pm and the Kahn test doubtful. A further laryngoscopic examination on March 1 revealed the following : the epiglottis, overhanging the cords and hiding the anterior commissure from view, was essentially unchanged in appearance as compared with the previous findings; the vocal cords appeared a little " motheaten" but moved quite normally. The patient's voice was no longer hoarse.

No further examination of the patient has been possible as he left London and his whereabouts are not known.

\section{Discussion}

By its well-known spirochaeticidal action, penicillin had initiated a massive destruction of treponemata (as evidenced by the Herxheimer reaction a few hours after the first dose), and a rapid healing of the syphilitic lesions, resulting in intensive tissue reactions with fibrosis at the site of laryngeal involvement. It is interesting to note that the laryngeal symptoms started to appear in the third week after commencing penicillin, in other words, in this case a local Herxheimer reaction was not noted, and, thus, the laryngeal complications were due to a resolution process in the syphilitic lesions ("therapeutic paradox"). The so-called therapeutic paradox is a not uncommon manifestation in penicillin-treated visceral syphilis. The factors which are necessary for its production seem to be

(a) syphilitic lesions in some vital organ such as an important artery, larynx, liver

(b) exhibition of a highly efficacious antisyphilitic drug such as penicillin.

It is important that the therapeutic paradox phenomenon be differentiated from the local Herxheimer reaction, which may occur during treatment with any of the specific drugs, and which is particularly dangerous when occurring in the brain, cardiovascular system, or larynx. Thus, Larmore (1947) noted acute obstruction of the airway in the course of administration of potassium iodide in patients with syphilitic laryngitis, and advocated a preliminary tracheotomy in some cases before giving the drug. There is some evidence that premedication with bismuth and iodides lessens considerably the incidence of Herxheimer reactions in cardiovascular syphilis, syphilitic hepatitis, and neurosyphilis. Would this premedication also lessen the likelihood of a therapeutic paradox phenomenon? No final answer can be given at present. If it is decided to use premedication, it should not be forgotten that the duration of treatment will be prolonged, and it is not difficult to understand how tempting it is to use penicillin immediately the diagnosis is made, especially in highly infectious cases of early syphilis.

\section{Summary}

Shortly after an intensive course of penicillin treatment of a highly infectious case of early syphilis with condylomata and " mucous patches", alarming signs of laryngeal involvement appeared. Its causation is not considered to be due to a local Herxheimer reaction in the larynx but to scarring and deformity, the end-result of the rapid healing of the syphilitic lesions in the epiglottis and vocal cords. These phenomena frequently occur in intensively-treated visceral syphilis and lead subsequently to the so-called therapeutic paradox.

My thanks are due to Dr. A. H. Harkness for his help and permission to publish this case, and to Dr. S. Silberman for reporting on the laryngoscopic appearances.

\section{REFERENCE}

Larmore, J. L. (1947). J. Indiana med. Ass., 40, 638. 